\title{
Frequency judgments and the spacing effect: Immediate and delayed performance
}

\author{
JAMES F. BRAY and DONALD ROBBINS \\ Emory University, Atlanta, Georgia 30322
}

\begin{abstract}
A study was conducted using a continuous paired-associate task varying the retention interval after one or two presentations of a pair of words. The lag between presentations was also varied. Half of the items were tested immediately, and all of the items were tested after a delay. Subjects were instructed to recall the response and to indicate the presentation frequency for each item. The results indicated a lag effect only for items correctly judged as repetitions at the time of test on both immediate and delayed tests. Overall responding was generally greater for items given an immediate test in contrast to those only given the delayed test. The role of variable encodings and the representation of frequency in memory is discussed.
\end{abstract}

It is a well-established finding that increasing the spacing or lag between repetitions of a word pair leads to better recall performance on a paired-associate task (see Hintzman, 1974 for a review). In addition, Peterson, Hillner, and Saltzman (1962) found the spacing effect only when the retention interval was relatively long. When the retention interval was relatively short, performance declined as the lag increased. This interaction has recently been replicated by Robbins and Bray (1974).

A major explanation for the lag effect is the encoding variability view (e.g., Bjork \& Allen, 1970; Melton, 1970). Melton (1970) assumes that increasing the lag leads to more variable encodings and thus a greater recall probability at the time of test. This view implies that items not correctly recognized on the second presentation should have more variable encodings and thus a higher recall probability. Bellezza, Winkler, and Andrasik (1975) recently found precisely the opposite result, namely that items recognized on the second presentation were more likely to be recalled than items not recognized.

However, recognition failure may not be essential for variable encodings. The results of Bellezza et al. (1975) may be accommodated by supplementing variable encodings with a notion of frequency representation in memory.

Hintzman and Block (1971) have proposed a multiple-trace hypothesis to account for frequency representation in memory. This view essentially states that each presentation establishes a single trace for that item in memory. Further, it is assumed that temporal separation favors trace discrimination. Thus, judgments of frequency depend on how well the

This research was supported in part by a grant from the Emory University Graduate School of Arts and Sciences and in part by Grant No. 5 T01 HD00208-07 from the National Institute of Child Health and Human Development. Requests for reprints should be sent to: D. Robbins. Department of Psychology, Emory University. Atlanta. Georgia 30322. memory traces for an item can be differentiated. For Hintzman and Block (1971), "time tagging" the traces is the basis for differentiating memory traces. Another basis, perhaps independent of time, may be differential encodings. Some support for this suggestion is derived from recognition studies that reveal lag effects when items are presented in the same context on both presentations, but no lag effect when the item is presented in two different contexts (e.g., Winograd \& Raines, 1972).

In the present study, subjects were given a continuous paired-associate study-test task and were required to estimate the presentation frequency as well as recall the response on test trials.

Another question of interest addressed here is the role or function of test trials. Test trials may function in a manner similar to study trials. For example, Izawa (1971) has found evidence, in a paired-associate task, that test trials serve to prevent forgetting. Similarly. Gotz and Jacoby (1974) found, in a free recall task, that final free recall was aided by initial recall and concluded that this enhancement results when the retrieval cues used at initial and final recall are similar. As a result, in this study half of the items were given only a delayed recall test while the remaining half had both an immediate and delayed test.

\section{METHOD}

\section{Design and Material}

A continuous paired-associate study-test procedure was used. The stimuli were medium imagery nouns, mean $=3.95$ (Paivio, Yuille. \& Madigan, 1968). Each subject received 12 pairs on each of nine conditions. Five of the conditions were single-presentation conditions followed by $1,3,5,7$, or 11 pairs or tests of other pairs and then a test trial. Since the trials were given at a 5-sec rate. the retention interval ranged from 5 and $55 \mathrm{sec}$ for these conditions. The other four conditions were repetition conditions representing a factorial combination of a lag of either 5 or $25 \mathrm{sec}$ and a retention interval of 5 or $25 \mathrm{sec}$. Half of these pairs were given immediate and delay tests, and the remaining half were given only a delayed test. Thus for these items the retention interval variable is a dummy 
variable, and these data are collapsed across this dummy variable. Filler items were inserted where necessary to obtain the appropriate spacing conditions. Approximately half of the filler items were presented once and the remaining items were presented twice. All of the filler items were tested although these data are note included in the analyses. The order of conditions was counterbalanced throughout the list. The first 12 items in the list were a practice series which also served as a primacy buffer. An additional six items at the end of the last list served as a recency buffer.

\section{Subjects}

A group testing procedure was used, and a total of 25 subjects was obtained from the introductory psychology subject pool and partially fulfilled a course requirement by participation in one 25-min session.

\section{Procedure}

the study and test trials were presented visually at a 5-sec rate with a projector, and each subject recorded responses on a separate answer sheet. On all test trials, the subjects were told to recall the response and to indicate the frequency of occurrence of each pair. After the completion of the task, the subjects were given a sheet which contained the stimulus terms from all of the experimental pairs in a random order. They were asked to write down as many of the responses as they could remember and to indicate the frequency of occurrence of each pair.

\section{RESULTS AND DISCUSSION}

The first result of interest shown in Table 1 can be seen in the columns marked "Total" for the repetition conditions on the immediate test. The failure to find a lag effect for the short retention interval $(5 \mathrm{sec})$ coupled with the large lag effect for the 25-sec retention interval condition is another replication of the interaction of lag and retention interval interaction found by Peterson et al. (1962) and confirmed by Robbins and Bray (1974). This was confirmed by a within-subject analysis of variance that revealed a significant Lag by Retention Interval interaction, $F(1,99)=9.89, p<.01$. Furthermore, Table 1 also shows the lag effect only for repetition items correctly judged as occurring twice. For those judged (incorrectly) as occurring only once, no lag effect can be seen. Although there are problems when one performs post hoc partitions of data, these results seem to be so striking that they at least warrant some consideration. Similar results can be seen in Table 1 for these items on the delayed tests. In addition, items only given the delayed test also show the same pattern of results.

The overall level of responding was higher for those items given an immediate test. As can be seen in Table 1, this was also the case for the single-presentation items. It is interesting to note that although a short retention interval led to superior performance for single-presentation items on immediate tests, these results essentially were reversed on the delayed test. These data are similar to those reported by Meunier, Ritz, and Meunier (1972) using a short-term memory task, Jacoby and Bartz (1972), using a free recall task, and Robbins and Bray (1974) using a continuous paired-associate task. The overall superiority of items given an immediate test may be taken as support for the suggestion that test trials may function in a manner similar to presentation trials. It should be noted that the results here are not entirely unambiguous. For example, only $5 \%$ of the single-presentation items tested $25 \mathrm{sec}$ later were recalled on the delayed test, in contrast to $15 \%$ for the repetition condition with a lag of $5 \mathrm{sec}$. However, $18 \%$ of the single-presentation items with a 25-sec retention interval were recalled on the delayed test, in contrast to $17 \%$ for the $25-\mathrm{sec}$ lage-repetition condition.

Table 1

Proportion Correctly Recalled for the Various Conditions

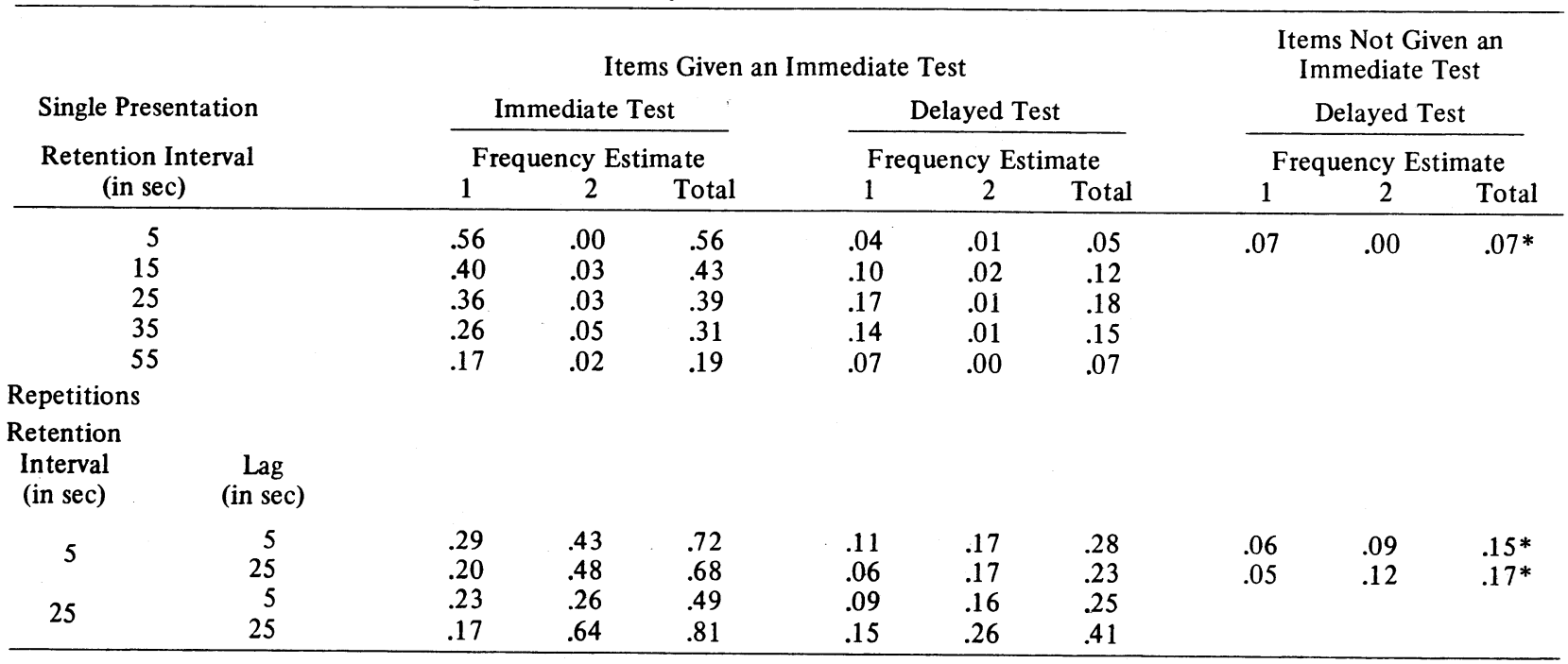

*The retention interval variable was an irrelevant variable for items only given delayed test so that these items are presented here for ease of presentation. 
The finding of a lag effect only when subjects correctly judged the presentation frequency supports the combined variable-encoding-multiple-trace hypothesis suggested here. However, it should be pointed out that other representations of frequency (see Howell, 1973) may also be accommodated although Wells (1974) has recently concluded a strength theory of frequency is not a viable hypothesis.

\section{REFERENCES}

Bellezza, F. S., Winkler, H. B., \& Andrasik, F., JR. Encoding processes and the spacing effect. Memory \& Cognition. 1975, 3, 451-457.

Bjork, R. A., \& Allen, T. W. The spacing effect: Consolidation or differential encoding? Journal of Verbal Learning and Verbal Behavior, 1970, 9, 567-572.

Gotz. A., \& JACOBY, L. L. Encoding and retrieval processes in long-term retention. Journal of Experimental Psychology, 1974, 102, 291-292.

Hintzman, D. L. Theoretical implications of the spacing effect. In R. L. Solso (Ed.), Theories in cognitive psychology: The Loyola Symposium. Potomac, Maryland: Erlbaum, 1974.

Hintzman, D. L., \& Block, R. A. Repetition and memory: Evidence for a multiple-trace hypothesis. Journal of Experimental Psychology, 1971, 88, 297-306.

Howell, W. C. Representation of frequency in memory. Psychological Bulletin, 1973, 80, 44-53.
Izawa, C. The test trial potentiating model. Journal of Mathematical Psychology, 1971, 8, 200-224.

JACOBY, L. L., \& BARTZ, W. H. Rehearsal and transfer to LTM. Journal of Verbal Learning and Verbal Behavior, 1972, 11, 561-565.

Melton, A. W. The situation with respect to the spacing of repetitions and memory. Journal of Verbal Learning and Verbal Behavior, 1970, 9, 596-606.

Meunier, G. F., Ritz, D., \& Meunier, J. A. Rehearsal of individual items in short-term memory. Journal of Experimental Psychology, 1972, 95, 465-467.

Paivio, A., Yuille, T. C., \& Madigan, S. Concreteness, imagery, and meaningfulness values for 925 nouns. Journal of Experimental Psychology, 1968, 70 (1, part 2).

Peterson, L. R., Hillner, K., \& Saltzman, D. Time between pairings in short-term retention. Journal of Experimental Psychology, 1962, 64, 550-551.

RobBins, D., \& BRAY, J. F. Repetition effects and retroactive facilitation: Immediate and delayed test performance. Bulletin of the Psychonomic Society, 1974, 3, 347-349.

Wells, J. E. Strength theory and judgments of recency and frequency. Journal of Verbal Learning and Verbal Behavior, 1974, 13, 378-392.

Winograd, E., \& RAines, S. R. Semantic and temporal variation in recognition memory. Journal of Verbal Learning and Verbal Behavior, 1972, 11, 114-119.

(Received for publication October 1, 1975.) 